\title{
Dysphagia Due to an Esophageal Polyp After Gastric Bypass
}

\author{
Dina Podolsky, MD, Erin Moran-Atkin, MD, Jenny J. Choi, MD, Diego Camacho, MD \\ Department of Surgery, Montefiore Medical Center, Bronx, New York, USA (all authors).
}

\begin{abstract}
Introduction: Hyperplastic inflammatory polyp (HIP) is an overgrowth of gastric mucosa associated with underlying chronic inflammation. Usually located in the gastric corpus and antrum, it has also been known to arise at the gastroesophageal (GE) junction.
\end{abstract}

Case Description: We report a case of a large HIP located at the GE junction causing dysphagia in a patient who recently underwent a Roux-en-Y gastric bypass. The polyp was removed endoscopically with resolution of the patient's symptoms.

Discussion: We present an unusual case of HIP, the first such case in our experience, and report the successful restoration of oral intake in the patient.

Key Words: Hyperplastic, Polyp, Obstruction, Gastric bypass.

\footnotetext{
Citation Podolsky D, Moran-Atkin E, Choi J, Camacho D. Dysphagia due to an esophageal polyp after gastric bypass. CRSLS e2016.000100. DOI: 10.4293/CRSLS.2016.000100.

Copyright (C) 2017 by SLS, Society of Laparoendoscopic Surgeons. This is an open-access article distributed under the terms of the Creative Commons Attribution-Noncommercial-ShareAlike 3.0 Unported license, which permits unrestricted noncommercial use, distribution, and reproduction in any medium, provided the original author and source are credited.

Disclosures: none reported

Address correspondence to: Dina Podolsky, MD, 3450 Wayne Avenue, Apt. 10P, Bronx, NY 10467. Telephone: 201-738-0288. E-mail: dpodolsk@montefiore.org
}

\section{INTRODUCTION}

Hyperplastic inflammatory polyp (HIP) is an overgrowth of gastric mucosa commonly associated with chronic gastritis. ${ }^{1}$ Usually located in the gastric corpus and antrum, it has also been known to arise at the gastroesophageal (GE) junction. We present a case of oral intake intolerance secondary to an obstructing polyp at the GE junction after a Roux-en-Y gastric bypass.

\section{CASE DESCRIPTION}

A 33-year-old woman with a history of diabetes mellitus, gastroesophageal reflux disease (GERD), and morbid obesity (body mass index, 59) presented to our clinic for evaluation for Roux-en-Y gastric bypass. A year before her procedure, the patient underwent an esophagogastroduodenoscopy (EGD) by a gastroenterologist, and at that time, no pathologic condition was seen. The patient completed an appropriate workup, including a preoperative assessment by the endocrinology, medicine, and pulmonary teams and was cleared for surgery. The laparoscopic Roux-en-Y gastric bypass was uneventful and was completed in the following fashion: a $50-\mathrm{cm}$ biliopancreatic limb was measured from the ligament of Treitz, a side-toside, linear-stapled jejunojejunostomy was created, and an alimentary limb was measured to $150 \mathrm{~cm}$. A gastric pouch was created with a series of linear staples. The Roux limb was brought up in an antecolic fashion, and a $25 \times$ 3.5-mm EEA Circular Stapler (Covidien; Medtronic, Minneapolis, Minnesota, USA) was used to create the gastrojejunostomy. The patient had an uncomplicated postoperative course and was discharged tolerating oral intake on postoperative day 2 .

On postoperative day 24 , the patient presented to the emergency department complaining of nausea and vomiting. An initial CT scan was nondiagnostic, and she was admitted to the surgical service for further workup. She underwent an upper gastrointestinal swallow test with contrast, which showed a filling defect in the distal esophagus, arousing suspicion of a bezoar (Figure 1).

The gastroenterology team was consulted, and the patient underwent an EGD, which revealed a 2-cm, friable, highly mobile polyp at the GE junction (Figure 2), causing a ball-and-valve effect in the esophagus (Figure 3). The EGD also showed that the entire gastric mucosa was diffusely erythematous. The obstructing polyp was re- 


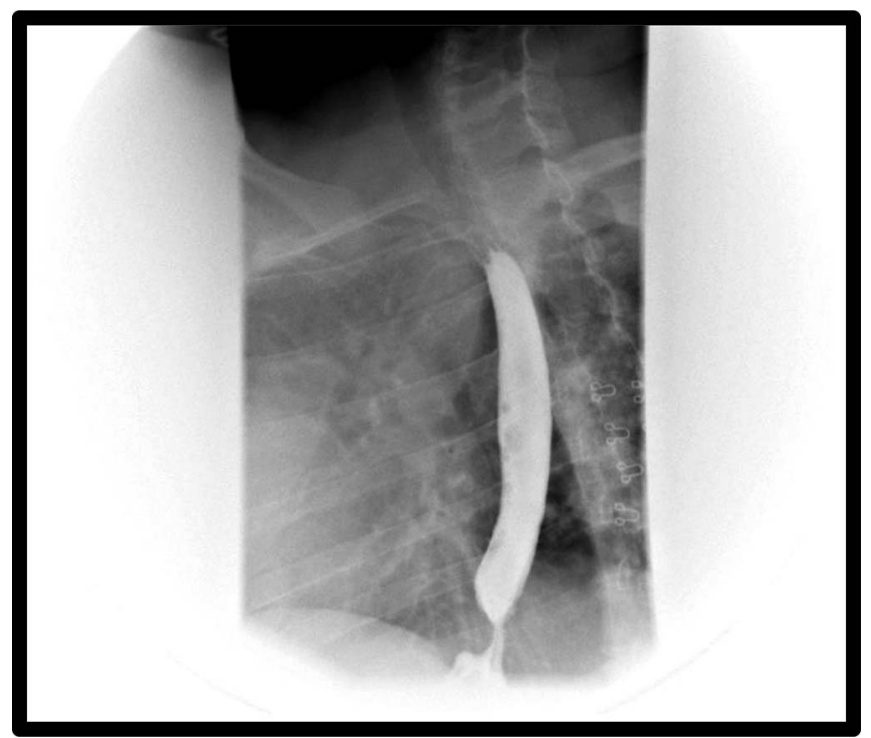

Figure 1. Esophagogram showing a distal filling defect remarkable for a mass.

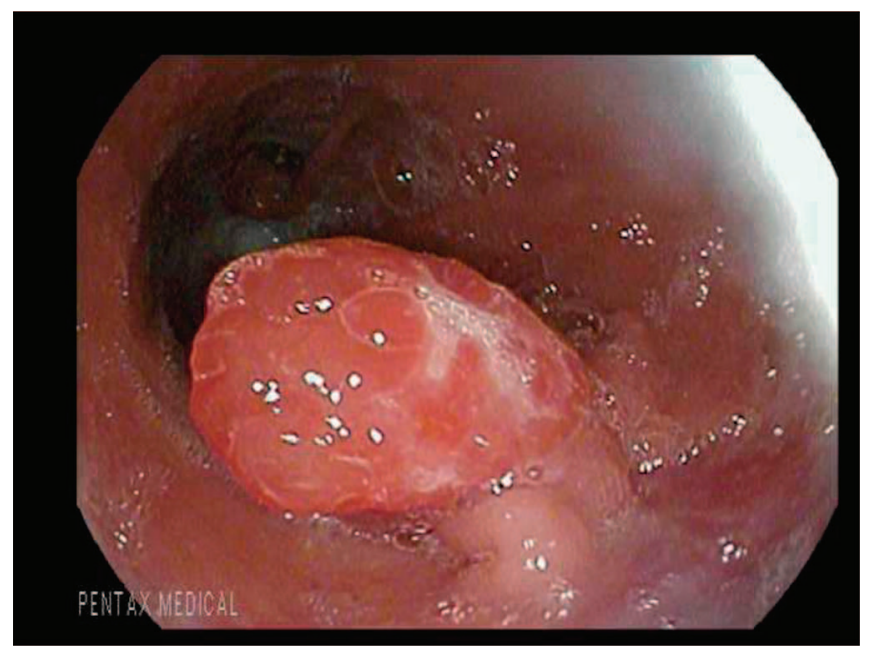

Figure 2. Hyperplastic polyp at the gastroesophageal junction.

moved by snare polypectomy (Figure 4), with pathology revealing a HIP with negative margins. The patient improved after the procedure and was discharged with outpatient follow-up.

\section{DISCUSSION}

There is an association between HIP arising in the GE junction and the presence of Barrett's esophagus. Most HIPs are small $(<2 \mathrm{~cm})$ and can be adequately treated with endoscopic removal. ${ }^{2}$ Although most of these polyps are benign, they may harbor malignant potential when

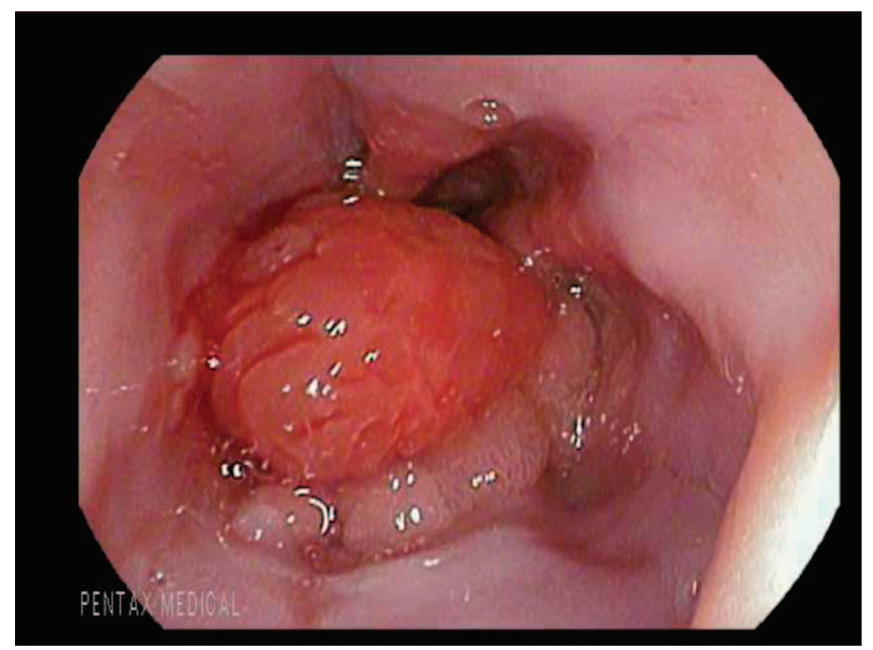

Figure 3. Polyp creating a ball-and-valve effect in the esophagus.

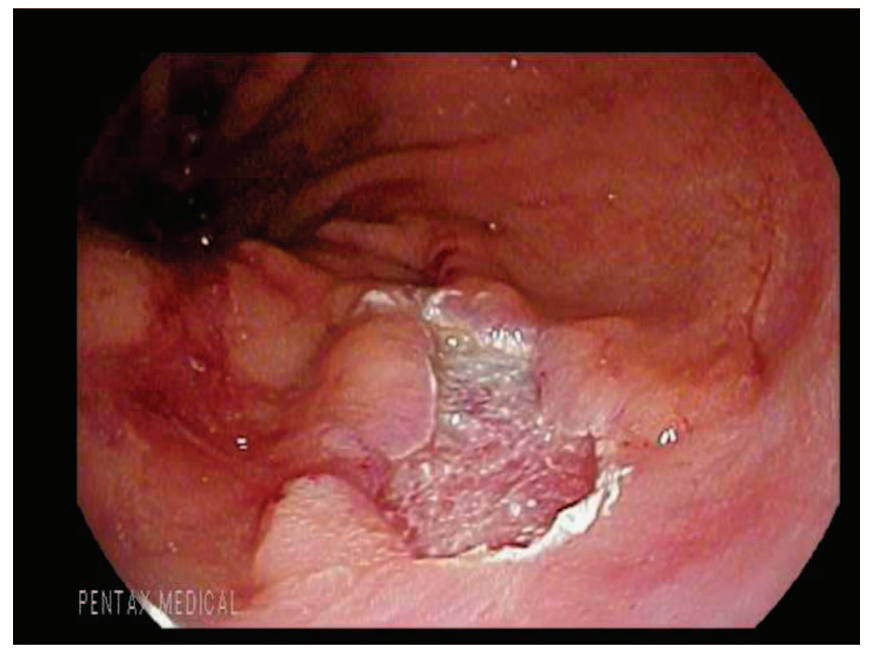

Figure 4. Site after the polypectomy.

larger than $1 \mathrm{~cm}$ in diameter or pedunculated. ${ }^{3}$ Therefore, all polyps greater than $0.5 \mathrm{~cm}$ should be removed when encountered during endoscopy.

Although most hyperplastic polyps are asymptomatic, large HIPs may present with symptoms such as bleeding and obstruction. ${ }^{3}$ When they present with obstruction, it is most frequently a gastric outlet obstruction caused by a very large hyperplastic polyp in the antrum of the stomach. On reviewing the literature, we found numerous case reports published on this very phenomenon. ${ }^{4}$ On the other hand, there is a scarcity of published literature on a hyperplastic polyp causing an obstruction at the GE junction, as was the case with our patient. In that sense, this patient's case presentation was unique in our experience. 
Our patient's history of GERD, combined with her recent gastric bypass, are identified risk factors for the development of an HIP: chronic mucosal irritation from gastric acid and bile reflux. GERD is a common complaint in morbidly obese patients, affecting nearly half of the population. ${ }^{5}$ Among the 3 most widely used bariatric procedures (gastric bypass, sleeve gastrectomy, and gastric lap banding), gastric bypass has been shown to be the most effective in reducing the symptoms of GERD as well as the amount of antireflux medication used. Bile gastritis is another known complication of gastric revisional surgery that has been associated with gastritis. ${ }^{6}$ Originally seen in patients with a short alimentary limb, this sequela has been mostly resolved by lengthening the alimentary limb to at least $100 \mathrm{~cm}$. The alimentary limb in our patient was measured to be $\sim 150 \mathrm{~cm}$ during the surgery, reducing but not entirely eliminating, the risk of bile gastritis.

Last, the decision to perform a preoperative EGD in patients who undergo bariatric surgery remains a clinical one. The current recommendations of various gastrointestinal societies, including the Society of American Gastrointestinal and Endoscopic Surgeons (SAGES) and the American Society for Metabolic and Bariatric Surgery (ASMBS), advise preoperative EGD only in patients with specific gastrointestinal symptoms. ${ }^{7,8}$ When indicated, the surgeon planning to perform a bariatric procedure should complete any preoperative EGD.

\section{CONCLUSION}

HIP is a known entity arising at the GE junction or intraluminally within the stomach. Our experience of an HIP causing obstruction at the GE junction in the setting of a recent gastric bypass procedure is a unique presentation of this process.

\section{References:}

1. Long KB, Odze RD. Gastroesophageal junction hyperplastic (inflammatory) polyps: a clinical and pathologic study of 46 cases. Am J Surg Pathol. 2011;35:1038-1044.

2. Islam RS, Patel NC, Lam-Himlin D, Nguyen CC. gastric polyps: a review of clinical, endoscopic, and histopathology features and management decisions. Gastroenterol Hepatol. 2013: 9:640-651.

3. Mhachai V, Graham DY, Odze RD. Gastric polyps. In: UpToDate, Post TW, ed. Deventer, The Netherlands: Wolters Kluwer, 2015.

4. Kosai NR, Gendeh HS, Norfaezan AR, Razman J, Sutton PA, Das S. Prolapsing gastric polyp causing intermittent gastric outlet obstruction. Int Surg. 2015;100:1148-1152.

5. Pallati PK, Shaligram A, Shostrom VK, Oleynikov D, McBride $\mathrm{CL}$, Goede MR. Improvement in gastroesophageal reflux disease symptoms after various bariatric procedures: review of the Bariatric Outcomes Longitudinal Database. Surg Obes Relat Dis. 2014;10:502-507.

6. Swartz DE, Mobley E, Felix EL. Bile reflux after Roux-en-Y gastric bypass: an unrecognized cause of postoperative pain. Surg Obes Relat Dis. 2009;5:27-30.

7. Mechanick JI, Youdim A, Jones DB, et al. Clinical Practice Guidelines for the Perioperative Nutritional, Metabolic, and Nonsurgical Support of the Bariatric Surgery Patient: 2013 Update. Cosponsored by American Association of Clinical Endocrinologist, The Obesity Review, and American Society for Metabolic and Bariatric Surgery. Obesity. 2013;21:S1-S27.

8. Society of American Gastrointestinal and Endoscopic Surgeons. Guidelines for Clinical Application of Laparoscopic Bariatric Surgery. Available at: https://www.sages.org/ publications/guidelines/guidelines-for-clinical-applicationof-laparoscopic-bariatric-surgery. Accessed December 10, 2016. 